\title{
Risk factors and a predictive model for under-five mortality in Nigeria: evidence from Nigeria demographic and health survey
}

\author{
Gbenga A Kayode ${ }^{1,2^{*}}$, Victor T Adekanmbi ${ }^{1,2}$ and Olalekan A Uthman ${ }^{1,2}$
}

\begin{abstract}
Background: Under-5 mortality is a major public health challenge in developing countries. It is essential to identify determinants of under-five mortality (U5M) childhood mortality because these will assist in formulating appropriate health programmes and policies in order to meet the United Nations MDG goal. The objective of this study was to develop a predictive model and identify maternal, child, family and other risk factors associated U5M in Nigeria.

Methods: Population-based cross-sectional study which explored 2008 demographic and health survey of Nigeria (NDHS) with multivariable logistic regression. Likelihood Ratio Test, Hosmer-Lemeshow Goodness-of-Fit and Variance Inflation Factor were used to check the fit of the model and the predictive power of the model was assessed with Receiver Operating Curve (ROC curve).

Results: This study yielded an excellent predictive model which revealed that the likelihood of U5M among the children of mothers that had their first marriage at age 20-24 years and $\geq 25$ years declined by $20 \%$ and $30 \%$ respectively compared to children of those that married before the age of 15 years. Also, the following factors reduced odds of U5M: health seeking behaviour, breastfeeding children for > 18 months, use of contraception, small family size, having one wife, low birth order, normal birth weight, child spacing, living in urban areas, and good sanitation.
\end{abstract}

Conclusions: This study has revealed that maternal, child, family and other factors were important risk factors of U5M in Nigeria. This study has identified important risk factors that will assist in formulating policies that will improve child survival.

\section{Background}

Childhood mortality is a prominent public health issue. Globally, mortality in under-five age children is about 9 million deaths per year and $70 \%$ are preventable which makes this an important public health problem to investigate [1]. In one of the series on child survival published on Lancet, childhood mortality was described as public-health disaster [2]. Children in developing countries are 10 times as more likely to die before their fifth birthday compared to those in developed countries [1]. The gap in childhood mortality between developed nations and developing nations has been increasing over a long period of time [3]. In response to the burden of

\footnotetext{
* Correspondence: gakayode@yahoo.co.uk

'Department of Public Health \& Biostatistics, University of Birmingham, Birmingham, UK

Full list of author information is available at the end of the article
}

childhood mortality in sub-Saharan Africa countries, United Nations and World Health Organization (WHO) has incorporated reduction of childhood mortality by two-third by the year 2015 as one of its Millennium Development Goals (MDGs).

Identifying determinants of under-five mortality (U5M) is essential for formulating appropriate health programmes and policies in order to meet the United Nations MDG goal (i.e. to reduce childhood mortality by two-third by 2015). Several studies have been conducted to identify the determinants of U5M. Studies have identified strong associations between maternal factors and childhood mortality. Maternal age has been shown to have a strong association with child survival [4-8]. However some of these studies did not consider certain important covariates such as sanitation, immunization, breastfeeding and previous child deaths in their 
research which might have confounding effect. Studies have also shown that children of educated mothers will survive better than children of non-educated mothers [5,9-15]. However another author has reported that maternal education has little or no effect on child survival [16].

Birth interval has been identified by numerous studies as a major determinant of childhood mortality $[4,7,9,13,17-20]$ although not all of these studies have considered potential confounders like breastfeeding, intra-familial mortality risks (survival status of preceding child), and multiple pregnancy etc. Grand multiparity has been revealed to have a negative effect on child survival $[10,15]$ Similarly, large family size has also been indicated to have a close association with poor rates of child survival. This was explained by increased intrafamiliar competition for foods and other limited resources essential for child survival $[13,19]$. Availability of accessible health care services have been reported to have an inverse relationship with childhood mortality $[4,10,21,22]$. Despite these preponderance of evidence about the determinants of childhood mortality from different parts of the world, the majority of the studies did not consider the potential effects of some of the important confounders in their analyses [4-9,13,18,20]. Moreover, there are few good studies from Nigeria and most of which did not use national representative data [23-28]. Thus, the generalizability of the results is a serious problem in a country like Nigeria because of her diversity. The most recent national representative 2008 Nigerian Demographic and Health Survey (NDHS) [29] has estimated U5M rate at 157 children per 1,000 live births compared to their counterpart in the United Kingdom (England and Wales) which was said to be 2.8 children per 1,000 live births [30]. It means that 1 out of 6 children will before their fifth birthday in Nigeria [29]. It is therefore important to the explore the latest Nigeria Demographic and Health Survey data to identify the determinants responsible for the persistently high under-5 mortality in Nigeria. The objective of this study was to develop a predictive model and identify maternal, child, family and other risk factors associated U5M in Nigeria.

\section{Methods \\ Setting}

Nigeria is situated in the West Africa region with a total area of 923,768 kilometre square $(\mathrm{km} 2)$, making it the fourteenth largest countries in Africa. Nigeria is lying between longitudes $2^{\circ} 40^{\prime}$ and $14^{\circ} 41^{\prime} \mathrm{E}$ and latitudes $4^{\circ} 16^{\prime}$ and $13^{\circ} 53^{\prime} \mathrm{N}$. Nigeria shared boundary with Niger at the northern part, Benin Republic at the western part, Cameroon at the eastern part and the Atlantic Ocean at the southern part of the country.
Nigeria is the most populous country in Africa and the most populous blacks' nation in the world. Nigeria population census 2006 was estimated at 140,431,790 with national growth rate of $3.2 \%$ per annum. The population density of Nigeria was estimated at 150 people per square kilometre. The country has over 250 ethnic groups [31,32] with varying languages and customs, creating a country of rich ethnic diversity. The ethnic groups are the Fulani/Hausa, Yoruba and Igbo accounting for $68 \%$ of the population while the Edo, Ijaw, Kanuri, Ibibio, Ebira, Nupe and Tiv comprise $27 \%$. The remaining minorities accounted for the $5 \%$. According to 2008 National Demographic and Health Survey, [29] children under -five accounted for $17.1 \%$ of the Nigeria population which makes every unit change in mortality to reflect great effect in the population. Also $33 \%$ of the total population is situated urban areas while $67 \%$ of the population were residing in rural areas. It has a GDP of about 200 billion United States dollars [33].

\section{Study design}

This is a secondary analysis of population-based crosssectional study which investigated the roles of child, maternal, paternal, family and other factors in U5M in Nigeria using the 2008 National Demographic and Health Survey data.

\section{Sampling technique}

Detail information about the sampling technique that was applied for the data collection had been published in the final report of 2008 NDHS [29]. The NDHS was designed to yield a national representative data. Nigeria is made up of 36 states and Federal Capital Territory (FCT). Both states and FCT are subdivided into local government areas while each local government comprises of localities. The cluster unit was provided by the National Population Commission, based on the 2006 national census and is called a census enumeration area. Each locality comprises of census enumeration areas while each census enumeration area has at least 80 households (400 population). Stratified two-stage cluster randomised design was applied. The first stage was the allocation of 888 clusters among all the states and FCT. They were allocated among the states and FCT based on their size and rural/urban areas. The rural areas have 602 clusters while the urban areas got 286 clusters. Sample frame of households in each selected cluster was obtained and these households were randomly sampled from. At the end, the sampling procedure randomly selected a total of 36,800 households for an interview with a minimum of 950 and 41 households for interview in each state and cluster respectively. All women in each household within the age of 15-49 were 
interviewed; also all men age 15-59 in approximately half of the sampled households $(16,800)$ were interviewed.

\section{Data collection}

Detail information about the data collection and questionnaires has been published in the final report of 2008 NDHS [29]. Three types of questionnaires (household, women's and men's questionnaires) were used and faceto-face interviews were conducted. All women age 15-49 in each of the selected household were interviewed while all men within the age 15-59 in approximately half of the sampled households $(16,800)$. Information was obtained about the children and their mothers and household. Retrospective information was taken about under -5 children that died in the last five years i.e. from 2003 to 2008. The exercise started in June 2008 and was completed in October 2008.

\section{Ethical consideration}

Ethical approval for this project was obtained from Ethical Committee of ICF at Calverton, Maryland, USA and National Ethic Committee in Federal Ministry of Health, Abuja, Nigeria.

\section{Outcome variables}

Each woman interviewed in the survey was asked to provide a detailed history of all her live births in chronological order. Under-five mortality was defined as the probability of dying before completing the fifth birthday.

\section{Explanatory variables}

Selection of explanatory variables was based on previous studies $[5,7,9,10,13,15,18,34-42]$ it is important to mention that analytical framework for child survival in developing country also gave good insight about the selection of the explanatory variables [43]. The following factors were included in the study: Maternal (current age, education, occupation, parity, marital status, age at first marriage, family planning, preceding birth interval, breastfeeding and health seeking behaviour) Childhood (sex, birth order, birth weight); Household (family size, sanitation number of wives, wealth index, fuel and water sources); Paternal factors (age, occupation); and other factors (place of residence, ethnicity and geopolitical region). The asset-based approach was used to asses wealth index. Also, we generated health seeking behaviour by combining 5 variables (having health care card, attended antenatal care, delivered in a health facility, knowledge of oral rehydration solution and received anti-tetanus) with the aid of Principal Component Analysis (PCA).

\section{Statistical analysis}

Recoding and renaming were done for both Independent and dependent variables. One survival outcome variable was generated. Descriptive analysis of the variables was done. Univariable logistic regression was used to examine the association between the explanatory variables and the dependent outcome. Only explanatory variables that were statistically significant $(\mathrm{P}$-value $=$ 0.05) were incorporated into multivariable logistic regression. Likelihood Ratio test (LHR test) was used to test for the goodness of fit of the model. Receiver Operating Curve (ROC) was employed to examine the predictive power of the model. Hosmer-Lemeshow goodness-of-fit was used to examine the fitness of the model. Variance Inflation Factor (VIF) was used to check for multicollinearity. Predictive and complexity characteristics of the model were considered during modelling. Stata 11 software package was used for the analysis.

\section{Results}

\section{Sample characteristics}

Out of all the 28,647 children delivered by 28,647 mothers, 3,201 of these children died before their fifth birthday. This survey retrospectively covered from the year 2003 to 2008 . Over $50 \%$ of the mothers interviewed have no former education and more than one quarter of them married before the age of 15 years. Use of contraception method is still a major problem in Nigeria, close to $90 \%$ of the mothers interviewed were not using any type of family planning methods.

Over $70 \%$ of the respondents were living in rural areas and approximately $90 \%$ of households were using coal, charcoal and wood for their cooking. The majority of the households have no toilet facility and only $10.5 \%$ have modern toilet facilities. More than $50 \%$ of people interviewed were poor and did not have access to safe water supply. Over $80 \%$ of the mothers interviewed have adopted birth interval of $\geq 18$ months between their deliveries. Similarly, it was found that over $80 \%$ of the children were breastfed for more than 6 months. However approximately, one-third of the mothers were unemployed while almost half of the fathers interviewed were farmers and about two-third of them were having monogamous families. The result is shown Table 1

\section{Univariable analyses}

The results of univariable (unadjusted) analyses are shown in Table 2. Illiteracy, multi-parity and early pregnancy were inversely related to child survival. Odds of U5M among the children of mothers that have primary and secondary/higher education reduced by $17 \%$ and $42 \%$ respectively compared to children of mothers with 
Table 1 Statistical summary of the explanatory variables

\begin{tabular}{|c|c|c|}
\hline \multirow[t]{2}{*}{ EXPLANATORY VARIABLES } & \multicolumn{2}{|l|}{ SUMMARY } \\
\hline & NUMBER & PERCENTAGE (\%) \\
\hline \multicolumn{3}{|l|}{ Maternal factors } \\
\hline \multicolumn{3}{|l|}{ Maternal education } \\
\hline No education & 1,4418 & 50.3 \\
\hline Primary & 6,552 & 22.9 \\
\hline Secondary or higher & 7,677 & 26.8 \\
\hline \multicolumn{3}{|l|}{ Maternal occupation } \\
\hline Not working & 9,035 & 31.7 \\
\hline Business or cleric & 9,985 & 35.1 \\
\hline Manual & 9,470 & 33.2 \\
\hline \multicolumn{3}{|l|}{ Parity } \\
\hline 1 & 3,061 & 10.7 \\
\hline 2,3 and 4 & 13,759 & 48.0 \\
\hline$\geq 5$ & 11,827 & 41.3 \\
\hline \multicolumn{3}{|l|}{ Marital status } \\
\hline Never married & 506 & 1.8 \\
\hline Currently married & 27,378 & 95.6 \\
\hline Formerly married & 762 & 2.7 \\
\hline \multicolumn{3}{|l|}{ Maternal age } \\
\hline$\leq 20$ years & 3,319 & 11.6 \\
\hline $21-25$ years & 6,787 & 23.7 \\
\hline $26-30$ years & 8,157 & 28.5 \\
\hline 31-35 years & 5,043 & 17.6 \\
\hline$>35$ years & 5,341 & 18.6 \\
\hline
\end{tabular}

\begin{tabular}{lll}
\hline Maternal age at first marriage & & \\
$<15$ years & 7,967 & 28.3 \\
$15-19$ years & 12,706 & 45.2 \\
$20-24$ years & 5,243 & 18.6 \\
$\geq 25$ years & 2,225 & 7.9 \\
\hline
\end{tabular}

\section{Family planning}

No method

Folkloric/traditional

$24,952 \quad 87.1$

Modern

1,072

87.1

2,647

9.2

Preceding birth interval

\begin{tabular}{lll}
$<18$ months & 1,719 & 7.4 \\
$18-36$ months & 12,634 & 54.3 \\
$>36$ months & 8,902 & 38.3 \\
\hline Breastfeeding & & \\
$<6$ months & 4,722 & 17.5 \\
$6-12$ months & 6,266 & 23.2 \\
$>12-18$ months & 8,629 & 32.0 \\
$>18$ months & 7,351 & 27.3 \\
\hline
\end{tabular}

\section{Health seeking behaviour}

\begin{tabular}{lll} 
Very low & 6,860 & 25.7 \\
Low & 8,862 & 23.3 \\
Average & 5,704 & 21.4 \\
Good & 5,224 & 19.6 \\
\hline Child factors & & \\
\hline Sex & & \\
Male & 14,604 & 51.0 \\
Female & 14,043 & 49.0 \\
\hline
\end{tabular}

Table 1 Statistical summary of the explanatory variables (Continued)

\begin{tabular}{|c|c|c|}
\hline \multicolumn{3}{|l|}{ Birth order } \\
\hline 1 & 5,353 & 18.7 \\
\hline 2,3 or 4 & 13,069 & 45.6 \\
\hline$\geq 5$ & 10,225 & 35.7 \\
\hline \multicolumn{3}{|l|}{ Birth weight } \\
\hline Large & 13,012 & 46.5 \\
\hline Average & 10,732 & 38.4 \\
\hline Small & 4,239 & 15.1 \\
\hline \multicolumn{3}{|l|}{ Household factors } \\
\hline \multicolumn{3}{|l|}{ Family size } \\
\hline $1-5$ & 11,557 & 40.3 \\
\hline$>5$ & 17,090 & 59.7 \\
\hline \multicolumn{3}{|l|}{ Sanitation } \\
\hline Good toilet & 2,955 & 10.5 \\
\hline Bad toilet & 25,136 & 89.5 \\
\hline \multicolumn{3}{|l|}{ Fuel sources } \\
\hline Gas & 250 & 0.9 \\
\hline Kerosene & 3,606 & 12.7 \\
\hline Other & 24,518 & 86.4 \\
\hline \multicolumn{3}{|l|}{ No of wives } \\
\hline One wife & 18,063 & 66.4 \\
\hline Two or more wives & 9,128 & 33.6 \\
\hline \multicolumn{3}{|l|}{ Wealth index } \\
\hline Poor & 14,475 & 50.5 \\
\hline Middle & 5,609 & 19.6 \\
\hline Rich & 8,563 & 29.9 \\
\hline \multicolumn{3}{|l|}{ Water source } \\
\hline Safe water & 13,021 & 46.3 \\
\hline Unsafe water & 15,122 & 53.7 \\
\hline \multicolumn{3}{|l|}{ Paternal age } \\
\hline$<22$ years & 264 & 1.0 \\
\hline 22-30 years & 5,453 & 20.3 \\
\hline$>30-40$ years & 10,854 & 40.4 \\
\hline \multirow[t]{2}{*}{$>40-50$ years $>50$ years } & 7,011 & 26.0 \\
\hline & 3,277 & 12.2 \\
\hline \multicolumn{3}{|l|}{ Paternal occupation } \\
\hline Business or cleric & 7,815 & 28.1 \\
\hline Farming & 12,645 & 45.5 \\
\hline Manual & 7,312 & 26.3 \\
\hline \multicolumn{3}{|l|}{ Others factors } \\
\hline \multicolumn{3}{|l|}{ Residence } \\
\hline Rural & 21,034 & 73.4 \\
\hline Urban & 7,613 & 26.6 \\
\hline \multicolumn{3}{|l|}{ Ethnicity } \\
\hline Major & 16,838 & 59.1 \\
\hline Minor & 11,643 & 40.9 \\
\hline \multicolumn{3}{|l|}{ Region } \\
\hline North central & 5,046 & 17.6 \\
\hline North east & 6,559 & 22.9 \\
\hline North west & 7,947 & 27.7 \\
\hline South east & 2,450 & 8.6 \\
\hline South west & 3,327 & 11.6 \\
\hline South south & 3,318 & 11.6 \\
\hline
\end{tabular}


Table 2 Result of univariable analysis logistic regression for under-5 mortality

\begin{tabular}{llll}
\hline EXPLANATORY VARIABLES & & & \\
\hline & OR & P-value & (C.I) \\
\hline Maternal factors
\end{tabular}

Maternal education

\begin{tabular}{llll} 
No education & 1.00 & - & $(-)$ \\
Primary & 0.83 & 0.001 & $(0.76-0.91)$ \\
Secondary or higher & 0.58 & 0.001 & $(0.53-0.64)$ \\
\hline Maternal occupation & & & \\
Not working & 1.00 & - & $(-)$ \\
Business or cleric & 0.96 & 0.380 & $(0.88-1.05) \backslash$ \\
Manual & 1.02 & 0.683 & $(0.93-1.12)$ \\
\hline Parity & & & \\
1 & 1.00 & - & $(-)$ \\
2,3 and 4 & 1.60 & 0.001 & $(1.37-1.87)$ \\
$\geq 5$ & 2.31 & 0.001 & $(1.98-2.70)$ \\
\hline Marital status & & & \\
Never married & 1.00 & - & $(-)$ \\
Currently married & 1.38 & 0.047 & $(1.00-1.90)$ \\
Formerly married & 2.04 & 0.001 & $(1.41-2.96)$ \\
\hline
\end{tabular}

\begin{tabular}{llll}
\hline Maternal age & & & \\
$\leq 20$ years & 1.00 & - & $(-)$ \\
$21-25$ years & 0.83 & 0.006 & $(0.73-0.95)$ \\
$26-30$ years & 0.80 & 0.001 & $(0.71-0.91)$ \\
$31-35$ years & 0.86 & 0.024 & $(0.75-0.97)$ \\
$>35$ years & 0.99 & 0.837 & $(0.87-1.24)$ \\
\hline
\end{tabular}

\section{Maternal age at first marriage}

\begin{tabular}{llll}
$<15$ years & 1.00 & - & $(-)$ \\
15-19 years & 0.80 & 0.001 & $(0.74-0.87)$ \\
20-24 years & 0.67 & 0.001 & $(0.60-0.75)$ \\
$\geq 25$ years & 0.61 & 0.001 & $(0.52-0.72)$ \\
\hline Family planning & & & \\
No method & 1.00 & - & $(-)$ \\
Traditional & 0.45 & 0.001 & $(0.35-0.58)$ \\
Modern & 0.55 & 0.001 & $(0.47-0.65)$ \\
\hline Health Seeking Behaviour & & & \\
Low & 1.00 & - & $(-)$ \\
Average & 1.17 & 0.001 & $(1.07-1.27)$ \\
High & 0.55 & 0.001 & $(0.50-0.62)$ \\
\hline Preceding birth interval & & & \\
$<18$ months & 1.00 & - & $(-)$ \\
18-36 months & 0.49 & 0.001 & $(0.43-0.56)$ \\
$>36$ months & 0.30 & 0.001 & $(0.26-0.34)$ \\
\hline Breastfeeding & & & \\
$<6$ months & 1.00 & - & $(-)$ \\
6-12 months & 0.27 & 0.001 & $(0.24-0.30)$ \\
$>12-18$ months & 0.10 & 0.001 & $(0.08-0.11)$ \\
$>18$ months & 0.10 & 0.001 & $(0.08-0.11)$ \\
\hline Child factors & & & $(-)$ \\
\hline Sex & & & \\
Male & 1.00 & - & \\
Female & 0.87 & 0.001 & \\
\hline
\end{tabular}

Table 2 Result of univariable analysis logistic regression for under-5 mortality (Continued)

\begin{tabular}{|c|c|c|c|}
\hline \multicolumn{4}{|l|}{ Birth order } \\
\hline 1 & 1.00 & - & $(-)$ \\
\hline 2,3 or 4 & 0.87 & 0.011 & $(0.79-0.97)$ \\
\hline$\geq 5$ & 1.25 & 0.001 & $(1.12-1.38)$ \\
\hline \multicolumn{4}{|l|}{ Birth weight } \\
\hline Average & 1.00 & - & $(-)$ \\
\hline Large & 0.91 & 0.022 & $(0.83-0.99)$ \\
\hline Small & 1.39 & 0.001 & $(1.38-1.70)$ \\
\hline \multicolumn{4}{|c|}{ Paternal \& Family factors } \\
\hline \multicolumn{4}{|l|}{ Family size } \\
\hline $1-5$ & 1.00 & - & $(-)$ \\
\hline$>5$ & 0.77 & 0.001 & $(0.71-0.80)$ \\
\hline \multicolumn{4}{|l|}{ Sanitation } \\
\hline Good toilet & 1.00 & - & $(-)$ \\
\hline Bad toilet & 1.98 & 0.001 & $(1.69-2.31)$ \\
\hline \multicolumn{4}{|l|}{ Fuel source } \\
\hline Gas & 1.00 & - & $(-)$ \\
\hline Kerosene & 1.48 & 0.193 & $(0.82-2.69)$ \\
\hline Others & 2.66 & 0.001 & $(1.49-4.76)$ \\
\hline \multicolumn{4}{|l|}{ No of wives } \\
\hline One wive & 1.00 & - & $(-)$ \\
\hline More wives & 1.35 & 0.001 & $(1.25-1.46)$ \\
\hline \multicolumn{4}{|l|}{ Wealth index } \\
\hline Poor & 1.00 & - & $(-)$ \\
\hline Rich & 0.69 & 0.001 & $(0.64-0.74)$ \\
\hline \multicolumn{4}{|l|}{ Water source } \\
\hline Unsafe water & 1.00 & - & $(-)$ \\
\hline Safe water & 0.76 & 0.001 & $(0.70-0.82)$ \\
\hline \multicolumn{4}{|l|}{ Paternal age } \\
\hline$<22$ years & 1.00 & - & $(-)$ \\
\hline $22-30$ years & 1.27 & 0.285 & (0.82-1.96) \\
\hline$>30-40$ years & 1.23 & 0.339 & $(0.80-1.90)$ \\
\hline$>40-50$ years & 1.28 & 0.260 & (0.83-1.98) \\
\hline$>50$ years & 1.67 & 0.022 & $(1.08-2.59)$ \\
\hline \multicolumn{4}{|c|}{ Paternal occupation } \\
\hline Business/cleric & 1.00 & - & $(-)$ \\
\hline Farming & 1.18 & 0.001 & (1.08-1.29) \\
\hline Manual & 1.01 & 0.896 & $(0.91-1.12)$ \\
\hline \multicolumn{4}{|l|}{ Other factors } \\
\hline \multicolumn{4}{|l|}{ Residence } \\
\hline Rural & 1.00 & - & $(-)$ \\
\hline Urban & 1.53 & 0.001 & $(1.40-1.68)$ \\
\hline \multicolumn{4}{|l|}{ Ethnicity } \\
\hline Minors & 1.00 & - & $(-)$ \\
\hline Majors & 1.02 & 0.546 & (0.95-1.10) \\
\hline \multicolumn{4}{|l|}{ Regions } \\
\hline North central & 1.00 & - & $(-)$ \\
\hline North east & 1.29 & 0.001 & $(1.15-1.45)$ \\
\hline North west & 1.37 & 0.001 & $(1.22-1.53)$ \\
\hline South east & 1.15 & 0.0800 .918 & $(0.98-1.34)$ \\
\hline South west & 0.99 & 0.001 & $(0.86-1.15)$ \\
\hline South south & 0.64 & & $(0.54-0.75)$ \\
\hline
\end{tabular}


no education. The likelihood of U5M among the children of mothers of parity of 2-4 and $\geq 5$ increased by $60 \%$ and $131 \%$ respectively compared to children of nulliparous women; while odds of U5M among the children of mothers within the age of 21-25 years, 26-30 years and $31-35$ years were reduced by $17 \%, 20 \%$ and $14 \%$ respectively compared to the children of mothers at the age of 20 years and below. Likelihood of U5M in children of mothers that were currently married and those that were formerly married increased by $38 \%$ and $104 \%$ compared to children of mothers that have never married.

Before controlling for other factors, maternal age at the first marriage was also found to have significant effect on U5M; the likelihood of U5M among the siblings of mothers that married at the age of 15-19 years, 20 - 24 years, and $\geq 25$ years were found to reduce by $20 \%, 33 \%$ and $39 \%$ respectively compared to mothers that married before the age of 15 years. Similarly, odds of U5M among the children of mothers that embraced traditional and modern methods of contraception reduced by $55 \%$ and $45 \%$ respectively compared to mothers that did not use any contraception.

We found that health seeking behaviour has an impact on child survival; odds of having U5M among the siblings of mothers with the best health seeking behaviour reduced by $45 \%$ while those with average health seeking behaviour increased by $17 \%$ compared to the children of mothers with the worst health seeking behaviour. Adequate preceding birth interval, exclusive breastfeeding have protective effects on child survival. Likelihood of U5M among the siblings of mothers with a preceding birth interval of 18-36 months and > 36 months reduced by $51 \%$ and $70 \%$ respectively compared to mothers with a preceding birth interval of $<18$ months. Being breastfed for 6-12 months, > 12-18 months and > 18 months reduced odds of U5M by $73 \%, 90 \%$, and $90 \%$ respectively compared to children that were breastfed for $<6$ months.

In the unadjusted analyses, being a female reduced odds of U5M by $13 \%$ while having birth order of $2-4$ decreased odds of U5M by $13 \%$ but birth order of $\geq 5$ increased its by $25 \%$ compared to children having birth order of one. Likelihood of U5M in children with low birth weight increased by $39 \%$ while that of large birth weight reduced by $9 \%$ compared to children that have normal birth weight.

Bad toilet facilities, cooking fuel and polygamous families were found to have positive association with U5M before considering other factors. Homes with bad toilet facilities increased odds of U5M by $98 \%$ compared to homes with good toilet facilities. Similarly, living in homes that were using charcoal as fuel source increased odds of U5M by $166 \%$ compared to those using gas. In similar manner, polygamous families increased odds of U5M by $35 \%$ compared to children from monogamous families.

Wealth, safe water and small family size were found to have protective effects on U5M before adjusting for all other factors. Likelihood of U5M in children from rich families reduced by $31 \%$ compared to children from poor family while safe water reduced odds of U5M by $24 \%$ compared to unsafe water. Families of 5 members or less decreased likelihood of U5M by $23 \%$ compared to families having $>5$ members. Moreover, odds of $\mathrm{U} 5 \mathrm{M}$ in rural areas increased by $53 \%$ compared to urban areas while odds of U5M were noticed to vary across the regions; in North East and North West it was observed to increase by $29 \%$ and $37 \%$ respectively but reduced by $36 \%$ in the South compared to North Central.

\section{Multivariable results}

The results of multivariable analyses, where all factors were controlled for are shown in Table 3. Effect of maternal age at first marriage remained statistically significant. The likelihood of U5M among the siblings of women who married at age 20-24 years and $\geq 25$ years declined by $20 \%$ and $30 \%$ respectively compared to women who married below age 15 years. Similarly, use of contraception, preceding birth interval and breastfeeding were found independently to have protective effects on U5M. The likelihood of U5M in children of mothers that were using a folkloric or traditional method of contraception reduced by $31 \%$ compared to children of mothers that did not embrace the use of contraception. Odds of U5M in children with 18-36 months and > 36 months of birth intervals reduced by $70 \%$ and $91 \%$ respectively compared to those delivered within birth interval $<18$ months. These effects have trend. Breastfeeding found to reduce the odds of under- 5 mortality by $57 \%$ in those that were breastfed for more $>18$ months compared to those that were breastfed for $<6$ months.

Birth order, toilet facility and birth weight of the children were independently associated with the U5M. Odds of U5M among children with low birth weight at birth increased by $31 \%$ compared to children with normal birth weight. Also the likelihood of U5M in homes with bad toilet facilities increased by $77 \%$ compared to homes with good toilet facilities. Similarly, odds of U5M in children with birth order of 2-4 increased by $93 \%$ compared to children with birth order of one. Despite the adjustment for confounders the independent effect of health seeking behaviour of the mother on child survival has shown that odds of U5M among the children of mothers with average health seeking behaviour reduced by $94 \%$ compared to children of mothers with worst health seeking behaviour. 
Furthermore, in the multivariable model, large family size, residing in rural areas and having more than one wife, have negative impacts on child survival. It was found that residing in rural areas increased odds of U5M by 53\% compared to children living in urban settlements. Similarly, Odds of U5M in children from families with more than 5 members increased by $254 \%$ compared to children from families with less than 5 members. In the same manner, having more than one wife has been shown to have positive associations with U5M. Odds of U5M increased by $47 \%$ in polygamous families compared to monogamous families. Child survival in different regions also varied. The likelihood of under-5 mortality in children living in South East, Nigeria reduced by $54 \%$ compared to children that were living in the North central part of Nigeria when other confounders have been considered. Contrary to expectation, the likelihood of U5M in children living in homes where kerosene and charcoal were sources of energy reduced by $48 \%$ and $72 \%$ respectively compared to those using gas.

\section{Model fit and Predictive power of the models}

Likelihood ratio test (LHR test) and Hosmer-Lemeshow goodness-of-fit were used to examine the fitness of the model. None of these raise any question concerning the fitness of the models. Variance inflation factor (VIF) was employed to check for multicollinearity. None of the VIF values were up to 10 and the mean VIF of the model was less than 6 . It means there was no collinearity in the model (see additional file 1 ). Figure 1 shows the Receiver Operating Curve (ROC Curve). Area under the ROC curve was greater than $90 \%$ which means that the predictive power of the model was perfect. The positive predictive value was $66.7 \%$ and the negative predictive value was $96.4 \%$.

\section{Discussion}

The outcome of this study has shed more light on risk factors of U5M in Nigeria. This study has attempted to control for the effects of potential confounders by incorporating many factors into the analyses without overmodelling. Maternal age at first marriage was found to have an inverse relationship with U5M. This result shows that children of mothers that started childbearing at an early age were more prone to experience U5M more than those that commenced at an older age. This problem is now more pronounced because younger mothers formerly derived supports from mother in-laws and relatives that will stay with them for a long period of time but due to the economic crisis, this tradition has been eroded so young inexperience mothers have to take care of their children by themselves. Effect of maternal age at first marriage is consistent with other previous studies $[18,44]$.

The likelihood of U5M reduced in children of mothers that embraced the use of contraception. This study revealed that U5M were less likely to occur in children of mothers that adopted folkloric or traditional method of contraception than those that were not using any contraception. Contraception has a way of militating against incidence of unwanted pregnancy and it enhances adequate child spacing. It ensures that only children that were planned for will come to life and these will improve their survival. This relationship did not contradict what prior studies have reported $[8,13]$.

Birth interval was another important predictor of child survival. It has negative relationship with U5M. As child spacing increased, the likelihood of U5M reduced. This result supported what prior studies have reported $[4,7]$. Possible explanation for this is that mothers that waited for more than 18 months before having the next baby would have regained most body nutrients and blood loss during previous pregnancy and breast feeding. It is also a common medical knowledge that risk of obstetrics complications is higher in mothers that had short birth interval than those with long birth interval. Birth order was another determinant of child survival. It has a parallel association with U5M. The likelihood of U5M increased with increased in birth order of the child. This is consistent with other previous studies [5,45]. Possible mechanism for this is that as birth order increases, intra-familiar competition for foods and other limited resources essential for child survival will increase. Moreover, children are more prone to receive most impacts of it. Also as birth order increases level of child care reduces since the mother will have more children to care for.

It is important to mention that this study also revealed that children that were small at birth were more likely to die during before the age of 5 years than those that were having normal birth weight. A possible explanation for this, are the effects of preterm births. Most preterm children are more prone to have sepsis which is one of the leading causes of neonatal deaths. Other complications of preterm births are neonatal jaundice, apnoea etc. All these will account for high the likelihood of U5M in children with low birth weight. This is consistent with other previous studies $[7,8,10]$. This study has also shown that children raised in urban areas were more likely to survive better than those in rural areas. This finding supported what have been reported in other studies $[4,9,46]$. Likely explanation for this relationship is that children in urban areas have better access to health care services and all other essential health related services which are important for child survival. 
Table 3 Result of multivariable analysis logistic regression for under-5 mortality

\begin{tabular}{llll}
\hline EXPLANATORY VARIABLES & & & \\
\hline & OR & P-value & (C.I) \\
\hline Maternal factors & &
\end{tabular}

\section{Maternal education}

\begin{tabular}{llll} 
No education & 1.00 & - & $(-)$ \\
Primary & 0.98 & 0.742 & $(0.84-1.13)$ \\
Seconday or higher & 1.13 & 0.232 & $(0.92-1.38)$ \\
\hline Parity & & & \\
1 & 1.00 & - & $(-)$ \\
2,3 and 4 & $* * *$ & $* * *$ & $(-)$ \\
$\geq 5$ & $* * *$ & $* * *$ & $(-)$ \\
\hline Marital status & $* * *$ & $* * *$ & $(-)$ \\
\hline Maternal age & & & \\
$\leq 20$ years & 1.00 & - & $(-)$ \\
$21-25$ years & 1.23 & 0.113 & $(0.95-1.58)$ \\
26-30 years & 1.70 & 0.001 & $(1.30-2.22)$ \\
31-35 years & 2.48 & 0.001 & $(1.84-3.33)$ \\
$>35$ years & 2.87 & 0.001 & $(2.10-3.91)$
\end{tabular}

\begin{tabular}{llll}
\hline Maternal age at first marriage & & & \\
$<15$ years & 1.00 & - & $(-)$ \\
$15-19$ years & $* * *$ & $* * *$ & $(-)$ \\
$20-24$ years & 0.80 & 0.001 & $(0.70-0.90)$ \\
$\geq 25$ years & 0.70 & 0.001 & $(0.57-0.85)$
\end{tabular}

\begin{tabular}{llll}
\hline Family planning & & & \\
No method & 1.00 & - & $(-)$ \\
Traditional & 0.69 & 0.017 & $(0.51-0.85)$ \\
Modern & $* * *$ & $* * *$ & $(-)$ \\
\hline
\end{tabular}

\begin{tabular}{|c|c|c|c|}
\hline \multicolumn{4}{|c|}{ Health Seeking Behaviour } \\
\hline Low & 1.00 & - & $(-)$ \\
\hline Average & 0.06 & 0.001 & $(0.05-0.07)$ \\
\hline High & 1.00 & 0.951 & $(0.88-1.12)$ \\
\hline \multicolumn{4}{|c|}{ Preceding birth interval } \\
\hline$<18$ months & 1.00 & - & $(-)$ \\
\hline 18-36 months & 0.30 & 0.001 & $(0.26-0.34)$ \\
\hline$>36$ months & 0.09 & 0.001 & $(0.07-0.10)$ \\
\hline \multicolumn{4}{|l|}{ Breastfeeding } \\
\hline$<6$ months & 1.00 & - & $(-)$ \\
\hline 6-12 months & 1.00 & 0.955 & $(0.67-1.50)$ \\
\hline$>12-18$ months & 0.90 & 0.373 & $(0.71-1.14)$ \\
\hline$>18$ months & 0.43 & 0.001 & $(0.35-0.53)$ \\
\hline
\end{tabular}

\begin{tabular}{llll}
\hline Sex & & & \\
Male & 1.00 & - & $(-)$ \\
Female & 1.04 & 0.547 & $(0.92-1.17)$ \\
\hline Birth order & & & \\
1, & 1.00 & - & $(-)$ \\
2,3 or 4 & 1.93 & 0.001 & $(1.56-2.37)$ \\
$\geq 5$ & $* * *$ & $* * *$ & $(-)$ \\
\hline
\end{tabular}

\section{Birth weight}

Normal

1.00
Table 3 Result of multivariable analysis logistic regression for under-5 mortality (Continued)

\begin{tabular}{|c|c|c|c|}
\hline Large & 1.08 & 0.438 & $(0.87-1.27)$ \\
\hline Small & 1.31 & 0.004 & (1.09-1.58) \\
\hline \multicolumn{4}{|c|}{ Household factors } \\
\hline \multicolumn{4}{|l|}{ Family size } \\
\hline $1-5$ & 1.00 & - & $(-)$ \\
\hline$>5$ & 3.54 & 0.001 & $(3.07-4.08)$ \\
\hline \multicolumn{4}{|l|}{ Sanitation } \\
\hline Good toilet & 1.00 & - & $(-)$ \\
\hline Bad tiolet & 1.77 & 0.001 & $(1.46-2.14)$ \\
\hline \multicolumn{4}{|l|}{ Fuel source } \\
\hline Gas & 1.00 & - & $(-)$ \\
\hline Kerosene & 0.52 & 0.001 & $(0.44-0.63)$ \\
\hline Others & 0.28 & 0.001 & $(0.23-0.34)$ \\
\hline \multicolumn{4}{|l|}{ Wealth index } \\
\hline Poor & 1.00 & - & $(-)$ \\
\hline Rich & $* * *$ & $* * *$ & $(-)$ \\
\hline \multicolumn{4}{|l|}{ Water source } \\
\hline Unsafe water & 1.00 & - & $(-)$ \\
\hline Safe water & $* * *$ & $* * *$ & $(-)$ \\
\hline \multicolumn{4}{|l|}{ No of wives } \\
\hline One wife & 1.00 & - & $(-)$ \\
\hline More wives & 1.47 & 0.001 & $(1.30-1.66)$ \\
\hline \multicolumn{4}{|c|}{ Paternal occupation } \\
\hline Business/cleric & 1.00 & - & $(-)$ \\
\hline Farming & 0.82 & 0.121 & $(0.64-1.05)$ \\
\hline Manual & 0.87 & 0.328 & $(0.67-1.14)$ \\
\hline \multicolumn{4}{|l|}{ Other factors } \\
\hline \multicolumn{4}{|l|}{ Residence } \\
\hline Urban & 1.00 & - & $(-)$ \\
\hline Rural & 1.53 & 0.002 & $(1.16-2.00)$ \\
\hline \multicolumn{4}{|l|}{ Regions } \\
\hline North central & 1.00 & - & $(-)$ \\
\hline North east & 0.75 & 0.514 & $(0.31-1.78)$ \\
\hline North west & 0.67 & 0.366 & $(0.28-1.60)$ \\
\hline South east & 0.36 & 0.001 & $(0.32-0.42)$ \\
\hline South west & 0.99 & 0.497 & $(0.67-1.22)$ \\
\hline South south & 0.96 & 0.583 & $(0.83-1.11)$ \\
\hline
\end{tabular}

*** means variables omitted by StatalC 11 software package

This study revealed that good toilet facilities at home can reduce U5M and this is in line with other prior studies $[21,47,48]$. The outcome of this research has also shown that the number of wives that men married to, has a positive relationship with U5M. It was observed that as the number of wives increased, the likelihood of U5M in that family increased. This is consistent with previous study [49]. Possible reasons for this is intrafamiliar competition for food and other resources which are essential for child survival. Family size was noticed 


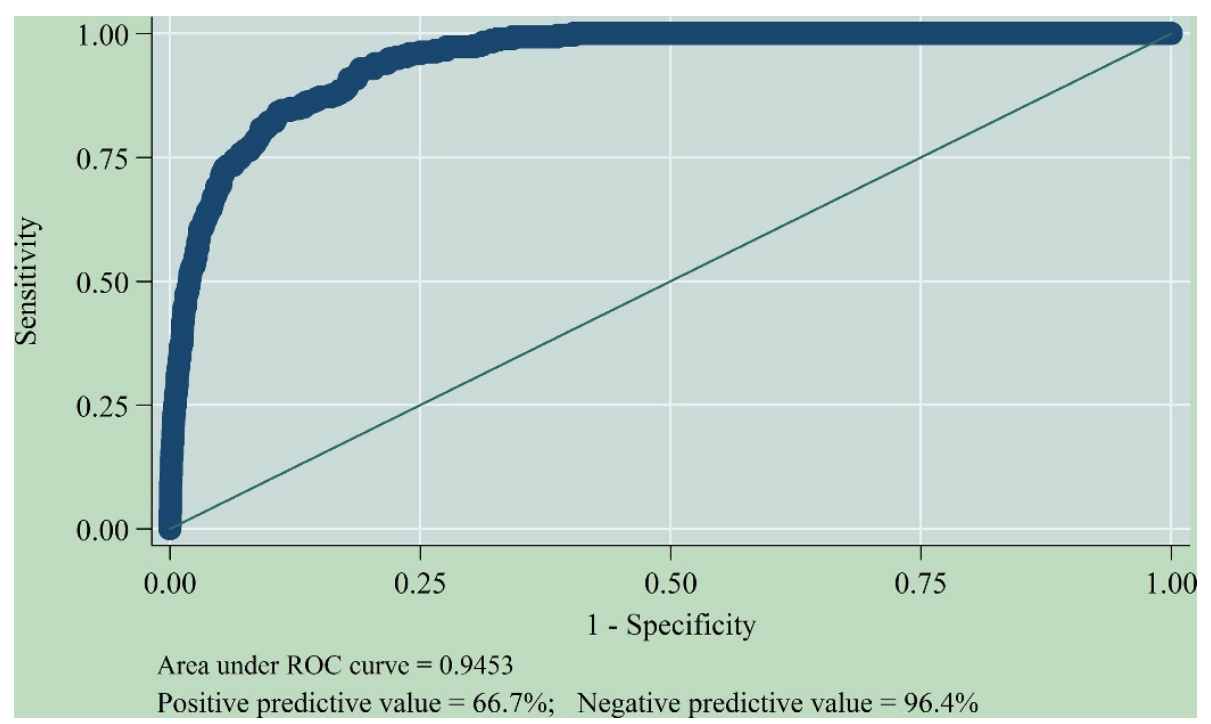

Figure 1 Receiver operating curve (ROC) of multivariable model for predicting under-five mortality, Nigeria 2003-2008

to have an independent effect on U5M. This phenomenon can be explained, based on the fact that as family size increases, intra-familiar competition for foods and other essential services require for child survival increases, so also parental attention for their children decreases. As a result of these U5M will increase.

Health seeking of mothers has been shown to have a positive impact on child survival. It is common medical knowledge that children of mothers that were in a good habit of seeking medical attention will allow their children to have the privilege of receiving immunization and treatment of preventable childhood diseases. Studies have shown that these services reduced U5M $[4,10]$. However, the trend was not found in this relationship. It is essential to report that this research yielded two skewed results although this could be explained. It was noticed that U5M started to increase from in mothers in the age group 26-30 years and the odds of U5M increased as the age group increased. Prior studies have reported two contrary views about the effect of maternal age on U5M. Some research reported that maternal aged has an inverse relationship with U5M $[23,26]$ while others revealed that it has no effect on U5M $[7,50]$. However, it is crucial to state that none of these studies considered maternal age at first marriage in their analyses, which was adjusted for in this study. Similarly, this study also revealed that child survival in homes that were using kerosene, fire woods and charcoals as sources of fuel would be better than those using gas. This was not in agreement with previous study [51]. Possible explanation for this is that, $<1 \%$ of the studied population were using gas.
Moreover survival of children living in South west of Nigeria was better than those residing in North central of Nigeria. Children in North central of Nigeria were more likely to die before their 5 th year birthday than their counterparts in North east of Nigeria. Prior study has also reported regional variations in child survival [52]. Possible explanation for these regional differences in child survival can be attributed to variations in vegetation across the regions. Children tend to survive better in regions with better agricultural output than regions with low output. Also the political will of government to implement good health policies varies across the regions.

\section{Strengths and weaknesses}

It is important to mention the strength and weaknesses of this study. This study is a population based cross sectional study with a large sample size that was randomly selected in order to reflect the true studied population. Thus, the findings of this study can be generalized to the studied population and to any other country's population similar to Nigeria. Possibility of selection and sampling bias in this study have been minimized because the whole country's population was considered before implementing stratified two-stage random sampling technique. Also the percentage of missing data in this study were negligible. However is also important to stress the weaknesses in this type of study. In this type of study, causal effect cannot be measured. Also the analysis of this study was based on point prevalence data; it is not possible to know whether the data are time dependent or not although 
the predictive power of the model have clarified this area. Generally, length bias is a common problem with this type of study.

\section{Recommendation}

$\mathrm{U} 5 \mathrm{M}$ in Nigeria is an urgent public health issue and appropriate measures are needed to be taken. This study has provided insights into the risk factors of U5M in Nigeria and this will be vital information for health policy makers in government and non-governmental organisation. Nigerian government and non-governmental organisation need to adopt programmes that will empower women because maternal factors were part of the major determinants of childhood mortality in Nigeria. Implementation of health programmes that will encourage breastfeeding, use of contraception and child spacing will go a long way in curtailing U5M in Nigeria.

Reorientation of parents concerning their health seeking behaviour via implementation of good health promotion programmes is highly essential to reduce U5M. It is important to mention that the Federal Ministry of Health, Nigeria needs to work in collaboration with other health related ministries such as the Federal Ministry of Agriculture, Education, Labour, Water and Federal Ministry of Women Affairs in order to reduce childhood mortality. This is because the provision of jobs and empowerment of women will have positive impacts on child survival. Enactment of laws that will ensure good sanitation should be in place in order to improve child survival.

Health inequality is another area that government and non-governmental organisation need to give urgent attention. This will improve equity among different regions and between rural and urban communities in Nigeria. In addition case-control study can be used to further investigate the effects of some of the factors. Maintaining small family size and encouraging monogamous family should be encouraged and promoted.

\section{Conclusions}

This study has revealed that maternal, child and family and other factors were the important determinants of U5M in Nigeria. It will be of great benefit if all these predictors could be properly considered during planning, formulation and implementation of policies that will improve child survival.

\section{Additional material}

Additional file 1: Result of test for multicollinearity in the multivariable model for under-5 mortality.

\section{Acknowledgements}

The authors are grateful to ICF macro (Calverton, USA) for providing the 2008 DHS data of Nigeria.

\section{Author details}

'Department of Public Health \& Biostatistics, University of Birmingham, Birmingham, UK. ${ }^{2}$ Centre for Evidence-Based Global Health, Ilorin, Kwara State, Nigeria.

\section{Authors' contributions}

GAK was involved in the conception of the study. GAK carried out data extraction. GAK conducted statistical analysis with contributions from VTA and OAU. GAK drafted the paper with contributions from VTA and OAU and GAK. All authors read and approved the final manuscript.

\section{Competing interests}

The authors declare that they have no competing interests.

Received: 17 September 2011 Accepted: 29 February 2012

Published: 29 February 2012

\section{References}

1. Children: reducing mortality. World Health Organization; 2012 [http:// www.who.int/mediacentre/factsheets/fs178/en/], Ref Type: Online Source.

2. Bawaskar HS: The world's forgotten children. Lancet 2003, 361:1224-1225.

3. State of the World's Children 2003. 2012 [http://www.unicef.org/ publications/files/pub_sow03_en.pdf], UNICEF Ref Type: Online Source.

4. Becher $\mathrm{H}$, Muller $\mathrm{O}$, Jahn A, Gbangou A, Kynast-Wolf G, Kouyate B: Risk factors of infant and child mortality in rural Burkina Faso. Bull World Health Organ 2004, 82:265-273.

5. Bhuiya A, Streatfield K: A hazard logit model analysis of covariates of childhood mortality in Matlab, Bangladesh. J Biosoc Sci 1992, 24:447-462.

6. Bobak M, Pikhart H, Koupilova I: Maternal socioeconomic characteristics and infant mortality from injuries in the Czech Republic 1989-92. Inj Prev 2000, 6:195-198.

7. Manda SO: Birth intervals, breastfeeding and determinants of childhood mortality in Malawi. Soc Sci Med 1999, 48:301-312.

8. Palloni A, Aguirre GP, Lastiri S: The effects of breast-feeding and the pace of childbearing on early childhood mortality in Mexico. Bull Pan Am Health Organ 1994, 28:93-111.

9. Adlakha AL, Suchindran CM: Factors affecting infant and child mortality. $J$ Biosoc Sci 1985, 17:481-496.

10. Bailey M: Individual and environmental influence on infant and child mortality in rural Sierra Leone: a multivariate analysis. Ren Kou Xue Kan 1989, 12:155-185.

11. Benefo K, Schultz TP: Fertility and child mortality in Cote d'Ivoire and Ghana. World Bank Econ Rev 1996, 10:123-158.

12. Buor D: Mothers' education and childhood mortality in Ghana. Health Policy 2003, 64:297-309.

13. Kumar G, Anand K, Kant S, Kapoor SK: Scale for identification of "at risk" families for underfive deaths. Indian J Pediatr 2000, 67:411-417.

14. Shah NM, Shah MA: Socioeconomic and health care determinants of child survival in Kuwait. J Biosoc Sci 1990, 22:239-253.

15. Van den Broeck J, Eeckels R, Massa G: Maternal determinants of child survival in a rural African community. Int J Epidemiol 1996, 25:998-1004.

16. Hobcraft J: Women's education, child welfare and child survival: a review of the evidence. Health Transit Rev 1993, 3:159-175.

17. Ikamari L: Birth intervals and child survival in Kenya. Afr J Health Sci 1998, 5:15-24.

18. Mturi AJ, Curtis SL: The determinants of infant and child mortality in Tanzania. Health Policy Plan 1995, 10:384-394.

19. Rutstein SO: Factors associated with trends in infant and child mortality in developing countries during the 1990s. Bull World Health Organ 2000, 78:1256-1270.

20. Rutstein SO: Effects of preceding birth intervals on neonatal, infant and under-five years mortality and nutritional status in developing countries: evidence from the demographic and health surveys. Int J Gynaecol Obstet 2005, 89(Suppl 1):S7-S24. 
21. Awasthi $\mathrm{S}$, Agarwal $\mathrm{S}$ : Determinants of childhood mortality and morbidity in urban slums in India. Indian Pediatr 2003, 40:1145-1161.

22. Frankenberg $E$ : The effects of access to health care on infant mortality in Indonesia. Health Transit Rev 1995, 5:143-163.

23. Adetunji JA: Infant mortality and mother's education in Ondo State, Nigeria. Soc Sci Med 1995, 40:253-263.

24. Caldwell JC: Education as a factor in mortality decline an examination of Nigerian data. Popul Stud 1979, 11:395-413.

25. Feyisetan BJ: Environmental sanitation and infant mortality: a study of relationships in Ile-Ife, Nigeria. Studies in Third World Societies 1985, 34:249-252.

26. Feyisetan BJ, Asa S, Ebigbola JA: Timing of births and infant mortality in Nigeria. Genus 1997, 53:157-181.

27. Oni GA: Child mortality in a Nigerian city: its levels and socioeconomic differentials. Soc Sci Med 1988, 27:607-614.

28. Folasade IB: Environmental factors, situation of women and child mortality in southwestern Nigeria. Soc Sci Med 2000, 51:1473-1489.

29. Nigeria Demographic and Health Survey, 2008. 2012 [http://www. measuredhs.com/pubs/pdf/FR222/FR222.pdf], Ref Type: Online Source.

30. Numbers and rates of registered deaths. World Health Organization; 2012 [http://apps.who.int/whosis/database/mort/table1_process.cfm], Ref Type: Online Source.

31. Background Note: Nigeria. 2012 [http://www.state.gov/r/pa/ei/bgn/2836. $\mathrm{htm}]$, Ref Type: Online Source.

32. Nigeria's Identifiable Ethnic Groups. 2012 [http://www.onlinenigeria.com/ tribes/tribes.asp], Ref Type: Online Source.

33. World Bank Data: Nigeria. 2012 [http://data.worldbank.org/country/ nigeria], Ref Type: Online Source.

34. Adetunji JA: Infant mortality in Nigeria: effects of place of birth, mother's education and region of residence. J Biosoc Sci 1994, 26:469-477.

35. Ahmad OB, Eberstein IW, Sly DF: Proximate determinants of child mortality in Liberia. J Biosoc Sci 1991, 23:313-326.

36. Andoh SY, Umezaki M, Nakamura K, Kizuki M, Takano T: Association of household demographic variables with child mortality in Cote d'Ivoire. J Biosoc Sci 2007, 39:257-265.

37. Gubhaju B, Streatfield K, Majumder AK: Socioeconomic, demographic and environmental determinants of infant mortality in Nepal. J Biosoc Sci 1991, 23:425-435.

38. Hull TH, Gubhaju B: Multivariate analysis of infant and child mortality in Java and Bali. J Biosoc Sci 1986, 18:109-118.

39. Majumder AK, Islam SM: Socioeconomic and environmental determinants of child survival in Bangladesh. J Biosoc SCi 1993, 25:311-318.

40. Nath DC, Land KC, Singh KK: Birth spacing, breastfeeding, and early child mortality in a traditional Indian society: a hazards model analysis. Soc Biol 1994, 41:168-180.

41. Singhi S, Kumar R, Raina N, Kumar V: Determinants of infant and child mortality in rural Haryana. Indian J Pediatr 1989, 56:753-763.

42. Sufian AJ: A multivariate analysis of infant mortality in developing countries. Nufusbil Derg 1990, 12:19-30.

43. Mosley WH, Chen LC: An analytical framework for the study of child survival in developing countries. 1984. Bull World Health Organ 2003, 81:140-145.

44. LeGrand TK, Mbacke CS: Teenage pregnancy and child health in the urban Sahel. Stud Fam Plann 1993, 24:137-149.

45. Vella V, Tomkins A, Nidku J, Marshall T: Determinants of child mortality in south-west Uganda. J Biosoc Sci 1992, 24:103-112.

46. Sastry N: What explains rural-urban differentials in child mortality in Brazil? Soc Sci Med 1997, 44:989-1002.

47. Abejo SD: Relationship of infant mortality and community development. Philipp Popul J 1987, 3:62-79.

48. Victora CG, Barros FC, Huttly SR, Teixeira AM, Vaughan JP: Early childhood mortality in a Brazilian cohort: the roles of birthweight and socioeconomic status. Int J Epidemiol 1992, 21:911-915.

49. Amankwaa AA: Prior and proximate causes of infant survival in Ghana, with special attention to polygyny. J Biosoc Sci 1996, 28:281-295.

50. Bailey M: Factors affecting infant and child mortality in rural Sierra Leone. J Trop Pediatr 1988, 34:165-168.

51. Ezzati M, Kammen DM: The health impacts of exposure to indoor air pollution from solid fuels in developing countries: knowledge, gaps, and data needs. Environ Health Perspect 2002, 110:1057-1068.
52. Casterline JB, Cooksey EC, Ismail AF: Infant and child mortality in rural Egypt. J Biosoc Sci 1992, 24:245-260

\section{Pre-publication history}

The pre-publication history for this paper can be accessed here: http://www.biomedcentral.com/1471-2393/12/10/prepub

doi:10.1186/1471-2393-12-10

Cite this article as: Kayode et al:: Risk factors and a predictive model for under-five mortality in Nigeria: evidence from Nigeria demographic and health survey. BMC Pregnancy and Childbirth 2012 12:10.

\section{Submit your next manuscript to BioMed Central and take full advantage of:}

- Convenient online submission

- Thorough peer review

- No space constraints or color figure charges

- Immediate publication on acceptance

- Inclusion in PubMed, CAS, Scopus and Google Scholar

- Research which is freely available for redistribution

Submit your manuscript at www.biomedcentral.com/submit
Ciomed Central 